\title{
Editorial
}

\section{Catalysis and Fine Chemicals}

\author{
Kotohiro Nomura ${ }^{1, * \mathbb{D}}$ and Boonyarach Kitiyanan ${ }^{2}$ \\ 1 Department of Chemistry, Graduate School of Science, Tokyo Metropolitan University (TMU), 1-1 Minami \\ Osawa, Hachioji, Tokyo 192-0397, Japan \\ 2 The Petroleum and Petrochemical College, Chulalongkorn University, Bangkok 10330, Thailand; \\ Boonyarach.K@chula.ac.th \\ * Correspondence: ktnomura@tmu.ac.jp
}

Received: 6 May 2020; Accepted: 7 May 2020; Published: 7 May 2020

check for updates

At the event of the International Symposium on Catalysis and Fine Chemicals 2018 (C\&FC2018, 10-14 December 2018, Chulalongkorn University, Bangkok, Thailand) organized by PETROMAT (co-organized by Chemical Society of Thailand and CATSJ), we decided to organize a Special Issue entitled "Catalysis and Fine Chemicals". The C\&FC originated from Tokyo, Japan in 2001, initially organized by the Catalysis and Fine Chemicals (C\&FC) division at the Catalysis Society of Japan (CATSJ). The symposiums were then held in Hong Kong (2004), Singapore (2007), Seoul Korea (2009), Nara, Japan (2011), Beijing, China (2013), Taipei, Taiwan (2016), and in Bangkok (2018). The projected fields in the C\&FC symposium covered are homogeneous and heterogeneous catalysis and organic, organometallic, inorganic, and bioinorganic chemistry. The topics in the symposium are selective catalytic reactions for synthesis of fine chemicals, new synthetic strategies and chemical processes, green and sustainable catalytic processes and reaction media, enhanced atom utilization, precise olefin polymerization, and industrial catalytic processes. There were more than 350 participants, including 4 plenary lectures and 9 keynote lectures, 71 invited lectures, 22 contributed papers, 8 young oral presentations, and 102 poster presentations. The symposium was very successful and we appreciate organization members who contributed to the C\&FC symposium.

Shown in Figure 1, the winners of the best poster presentation awards called the "Catalysts Award", sponsored by Catalysts are as follows.

(1) Siraphat Putisompon: Department of Chemistry, Mahidol University, Thailand; "Low-cost Catalyst for Glycolysis of Poly(ethylene) Terephthalate (PET)", see Figure 2A.

(2) Hanbyul Kim: Department of Chemistry, Hanyang University, Korea; "Asymmetric Synthesis of $\alpha, \beta$-Unsaturated- $\delta$-lactones via Gold(I)-Catalyzed Intermolecular [4+2] Annulation of Propiolates and Alkenes", See Figure 2B.

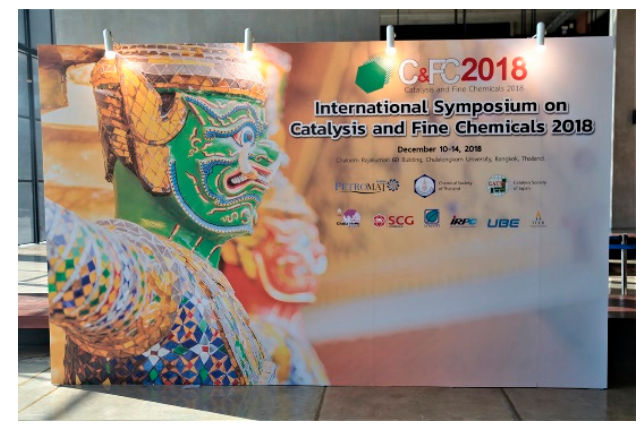

(A)

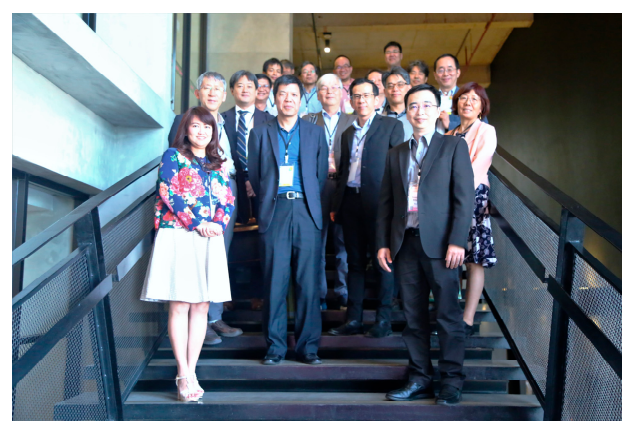

(B)

Figure 1. Announcement of the symposium at the entrance (A) and international advisory board, C\&FC2018 (B). 


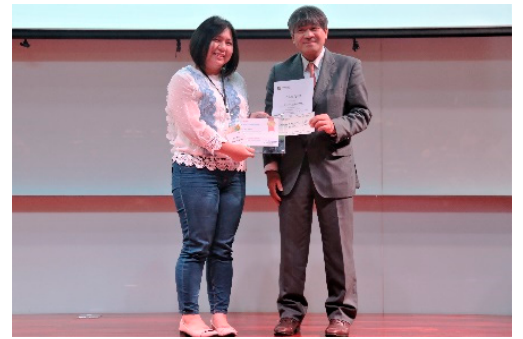

(A)

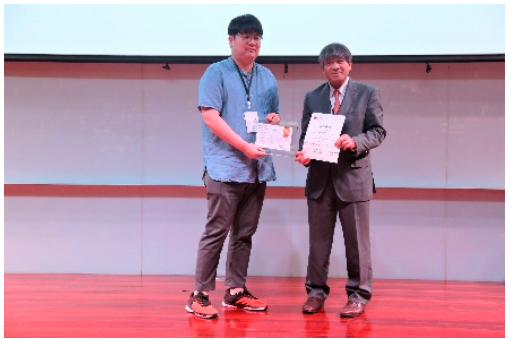

(B)

Figure 2. Kotohiro Nomura presented the poster presentation awards to Siraphat Putisompon (A) and Hanbyul Kim (B).

On the basis of success of the C\&FC symposium, we decided to make a Special Issue in Catalysts, consisting of seven papers [1-7], specifically from researchers from Thailand, Japan and China.

We hope that this would be a good opportunity to glance at the atmosphere in the C\&FC symposium in Bangkok.

Conflicts of Interest: The authors declare no conflict of interest.

\section{References}

1. Zhao, L.; Zhang, Y.; Wu, T.; Zhao, M.; Wang, Y.; Zhao, J.; Xiao, T.; Zhao, Y. Tuning Selectivity of Maleic Anhydride Hydrogenation Reaction over Ni/Sc-Doped $\mathrm{ZrO}_{2}$ Catalysts. Catalysts 2019, 9, 366. [CrossRef]

2. Yoshida, M.; Hirahata, R.; Inoue, T.; Shimbayashi, T.; Fujita, K.-I. Iridium-Catalyzed Transfer Hydrogenation of Ketones and Aldehydes Using Glucose as a Sustainable Hydrogen Donor. Catalysts 2019, 9, 503. [CrossRef]

3. Wang, Z.; Wang, X.; Nishihara, Y. $\mathrm{PPh}_{3}$-Assisted Esterification of Acyl Fluorides with Ethers via C( $\left.s p^{3}\right)-\mathrm{O}$ Bond Cleavage Accelerated by TBAT. Catalysts 2019, 9, 574. [CrossRef]

4. Unruean, P.; Plianwong, T.; Pruksawan, S.; Kitiyanan, B.; Ziff, R.M. Kinetic Monte-Carlo Simulation of Methane Steam Reforming over a Nickel Surface. Catalysts 2019, 9, 946. [CrossRef]

5. Poonsawat, T.; Techalertmanee, T.; Chumkaeo, P.; Yunita, I.; Meechai, T.; Namkajorn, M.; Pornsuwan, S.; Somsook, E. Facile Synthesis of High Performance Iron Oxide/Carbon Nanocatalysts Derived from the Calcination of Ferrocenium for the Decomposition of Methylene Blue. Catalysts 2019, 9, 948. [CrossRef]

6. Meeyoo, V.; Panchan, N.; Phongprueksathat, N.; Traitangwong, A.; Guo, X.; Li, C.; Rirksomboon, T. Low Temperature Methanation of $\mathrm{CO}_{2}$ on High Ni Content Ni-Ce-ZrO$\delta$ Catalysts Prepared via One-Pot Hydrothermal Synthesis. Catalysts 2020, 10, 32. [CrossRef]

7. Ngaotrakanwiwat, P.; Heawphet, P.; Rangsunvigit, P. Enhancement of Photoelectrochemical Cathodic Protection of Copper in Marine Condition by Cu-Doped $\mathrm{TiO}_{2}$. Catalysts 2020, 10, 146. [CrossRef]

(C) 2020 by the authors. Licensee MDPI, Basel, Switzerland. This article is an open access article distributed under the terms and conditions of the Creative Commons Attribution (CC BY) license (http://creativecommons.org/licenses/by/4.0/). 